\title{
A formação da ideia de nação nos jogos de reescrita do passado colonial em A gloriosa família e $\boldsymbol{O}$ outro pé da sereia
}

Kamila Krakowska

Universidade de Lisboa

RESUMO: ESTE ENSAIO ANALISA A CONSTRUÇÃO DA IDEIA DE NAÇÃO ATRAVÉS DA REESCRITA DO PASSADO COLONIAL EM DOIS ROMANCES LUSO-AFRICANOS CONTEMPORÂNEOS: A GLORIOSA FAMIILIA, DE PEPETELA, E O OUTRO PÉ DA SEREIA, DE MIA COUTO. A ESTRATÉGIA DE REESCRITA ESTÁ PRESENTE EM VÁRIOS NÍVEIS DOS TEXTOS, COM O INTUITO DE DESCONSTRUIR AS NARRATIVAS OFICIAIS DO COLONIALISMO. NESTE TRABALHO, TAIS "JOGOS DE HISTÓRIA" SÃO ESTUDADOS À LUZ DA TEORIA DE JOGOS DE LINGUAGEM DE LUDWIG WITTGENSTEIN.

ABSTRACT: THIS ESSAY ANALYSES THE CONSTRUCTION OF THE IDEA OF NATION BY RE-WRITING THE COLONIAL PAST IN TWO LUSO-AFRICAN CONTEMPORARY NOVELS, PEPETELA'S A GLORIOSA FAMILLIA, AND MIA COUTO'S O OUTRO PÉ DA SEREIA. THE STRATEGY OF RE-WRITING IS PRESENT IN VARIOUS LEVELS OF THE TEXTS, SO AS TO DECONSTRUCT THE OFFICIAL NARRATIVES OF THE COLONIALISM. IN THIS WORK, THESE “HISTORY GAMES" ARE STUDIED IN THE LIGHT OF LUDWIG WITTGENSTEIN'S THEORY OF LANGUAGE GAMES.

PALAVRAS-CHAVE: PEPETELA, MIA COUTO, HISTÓRIA, REESCRITA, NAÇÃO, PÓS-COLONIALISMO.

KEYWORDS: PEPETELA, MIA COUTO, HISTORY, REWRITING, NATION, POSTCOLONIALISM. 


\section{Introdução}

Os romances A gloriosa família, de Pepetela, e O outro pé da sereia, de Mia Couto, fazem parte do vasto processo da reescrita do passado histórico, procurando repensar aspectos da história colonial de Angola e Moçambique, respectivamente. A memória colonial, revista e reformulada, forja nestes textos um novo imaginário nacional que, adaptando a este caso particular a ideia de Homi Bhabha, passa a ser "o sujeito do discurso e o objeto da identidade psíquica” (BHABHA, 2005:217). O objectivo deste ensaio é analisar como o passado colonial é representado em $A$ gloriosa família e $O$ outro pé da sereia, e como esta visão pós-colonial da ocupação europeia do continente africano, confrontada com a historiografia portuguesa do período colonial, narra o surgimento e a formação das novas nações e das suas identidades.

O estudo focar-se-á em várias perspectivas no discurso histórico-literário presente nos romances citados. O método de análise é inspirado na teoria de Ludwig Wittgenstein sobre "jogos de linguagem”, definidos como a linguagem junto com todas as actividades envolvidas no acto de comunicação (WITTGENSTEIN, 1995:177). Os jogos wittgensteinianos servem como "objectos de comparação que por semelhança e dessemelhança irão esclarecer os factos da nossa linguagem" (WITTGENSTEIN, 1995:264). Em comparação, os jogos que apresentaremos irão esclarecer os factos da escrita da história e sobre a história.

\section{Os jogadores: Quem narra a nação?}

O objectivo central dos jogos de linguagem propostos por Wittgenstein é a comunicação. Por isso, os dois jogadores (o emissor e o destinatário) devem participar no acto linguístico. Caso um deles desista, o jogo acaba. De modo parecido, a comunicação entre o emissor e o destinatário também é vital para a construção de um discurso narrativo. Para assegurar este processo comunicativo, Umberto Eco sugere como estratégia literária que o autor deva "prever um Leitor-Modelo capaz de cooperar na actualização textual como ele, o autor, pensava, e de se mover interpretativamente tal como ele se moveu generativamente" (ECO, 1979:58). Nos romances analisados, a figura 
abstracta do Leitor-Modelo que orienta a construção do texto é adaptada para a própria narração, causando desdobramento e multiplicação das figuras de autor/narrador e leitor.

A gloriosa família: O tempo dos flamengos conta a história da ocupação de Luanda pelos holandeses nos anos 1641-1648, testemunhada pelo escravo de Baltazar Van Dum. O narrador descreve os acontecimentos que presencia ao acompanhar o seu dono, relatando os factos relacionados com a vida quotidiana da família, bem como o tráfico de escravos e a política envolvida no conflito colonial, porque sente "grande responsabilidade em ver e ouvir tudo para um dia poder contar, correndo as gerações, da mesma maneira que aprend[eu] com outros o que antes sucedeu" (PEPETELA, 2009:118). A sua consciência da história ultrapassa, porém, uma simples vontade de registar os factos, uma atitude cronista que governa a temporalidade da narração de A gloriosa família. O escravo compreende as limitações do discurso histórico que está modalizado pela visão ideológica do historiador/narrador. De facto, o narrador critica, por exemplo, os padres e, em geral, os europeus que negam aos povos colonizados o seu próprio sentido da história (PEPETELA, 2009:118), o que demonstra o seu conhecimento da influência das relações do poder na construção da história oficial. A personagem pepeteliana, como explica Ana Mafalda Leite, "transcende os limites da sua temporalidade ficcional e olha a História do seu Presente com o saber factual de um Futuro nela contido e actualizado" (LEITE, 2002:139-140).

Além dos comentários meta-históricos, a desconstrução do discurso histórico é realizada também pelo contraste entre verdade e imaginação. Por um lado, o narrador afirma: "tenho de ser imparcial e objectivo, o meu passado não interessa, apenas tenho de relatar os factos tal como os viveu o meu dono e a sua gloriosa descendência" (PEPETELA, 2009:251). Por outro lado, este observador "imparcial e objectivo" confessa abertamente que várias partes da sua narração foram imaginadas. A imaginação é a sua única forma de libertação da condição de escravo, permitindo "completar relatos que [lhe] são sonegados, tapando os vazios" (PEPETELA, 2009:14) e criar a sua história subjectiva. De facto, o escravo não narra os factos tal como ocorreram, mas, conforme observa Inocência Mata, "finge narrar", narrativizando a história (MATA, 2003:157). O contraste entre a atitude supostamente objectiva, factual e a recorrência constante à imaginação e à ficção provoca a desconstrução do relato histórico. 
A comunicação narrador-leitor fictício ${ }^{1}$ é estabelecida através deste jogo entre história e literatura. O escravo de Baltazar Van Dum assume que o seu relato vai chegar às gerações seguintes. No entanto, o carácter bilateral da relação entre a personagem do narrador e o leitor fictício é revelado apenas no final de $A$ gloriosa família, quando se torna óbvio que, ao nível da narrativa, foi um leitor que transmitiu o testemunho do escravo mudo e analfabeto, contado originalmente usando "poderes desconhecidos, dos que se ocultam no pó branco da pemba ou nos riscos traçados nos ares das encruzilhadas pelos espíritos inquietos" (PEPETELA, 2009:383). A comunicação entre o narrador-personagem e a figura do leitor que se torna o novo narrador da história remete ao processo da transmissão da literatura oral e da sabedoria tradicional de geração em geração pelos membros da comunidade. De facto, o escravo de Baltazar Van Dum, contando e imaginando o seu relato, não só desconstrói a visão ocidental da colonização de Angola, mas também desperta certo sentido de identidade; identidade de um povo que possui a sua narrativa, recontada com o passar do tempo, criando laços de pertença.

Em O outro pé da sereia, de Mia Couto, cruzam-se duas narrativas paralelas. A primeira é a história de Mwadia, em 2002 - uma jovem moçambicana que volta à sua aldeia natal para entregar à igreja uma misteriosa e antiga estátua de Nossa Senhora, salvando deste modo o seu marido. A segunda narrativa é constituída pelos manuscritos do relato da viagem de Goa a Moçambique no ano 1560 feita pelo jesuíta Dom Gonçalo de Silveira que leva para a corte do Monomotapa a imagem da santa, encontrada pelo marido de Mwadia quatro séculos mais tarde. As duas histórias são contadas por um narrador extradiagético e omnisciente. Porém, a relação supostamente simples e unívoca entre o narrador em terceira pessoa e o leitor torna-se complexa com o surgimento de vários narradores e leitores fictícios.

As etapas da missão evangélica são anotadas pelo escrivão oficial da expedição, padre Manuel Antunes e, mais tarde, por Silveira pessoalmente. No entanto, os seus diários serão lidos por Mwadia, por sua mãe, Dona Constança, e pelo barbeiro Arcanjo Mistura, os quais, a partir dos manuscritos encontrados, reinventam e recontam a história colonial. A polifonia das vozes

1. Neste trabalho, chamaremos "leitor fictício" o destinatário do relato do narrador ao nível da narrativa, seja ele uma personagem do romance ou uma figura abstracta criada na mente do narrador. 
destes narradores fictícios é unida numa narrativa coerente através do relato do narrador omnisciente. Este processo narrativo pode ser considerado uma variação do esquema de citação de várias vozes discursivas, analisado por Teresinha Taborda Moreira no seu estudo de vozes narrativas no romance moçambicano. A estudiosa explica que é a união de discursos de origem distinta, assegurada pela presença do narrador, que dá "significado ao texto na sua condição de entrecruzamento de margens” (MOREIRA, 2005:149).

Os diferentes discursos referidos pela investigadora brasileira surgem da coexistência e da hibridização das várias culturas que formam a identidade moçambicana. Assim, Dom Gonçalo de Silveira evoca o discurso colonial paternalista; Dona Constança simboliza a cultura tradicional e, em particular, a literatura oral africana; Mwadia, educada no Zimbabwe, mas fortemente ligada às crenças locais, procura incluir os mitos e as tradições antigas no discurso contemporâneo. Padre Manuel Antunes, o principal dos narradores fictícios de O outro pé da sereia, na sua função do escrivão nomeado pelo Vice-Rei, é obrigado a relatar todos os acontecimentos tanto da viagem marítima como da expedição na costa africana. Porém, com o passar do tempo, com a observação do comportamento dos brancos e da situação dos escravos, o padre começa a considerar o acto de escrever um fardo. Desesperado, lança o caderno no fogo porque as palavras "preenchiam-no a ele, proprietário de cada coisa descrita" (COUTO, 2006:186).

Contudo, a personagem volta a relatar os acontecimentos testemunhados na viagem, quando se apercebe que o seu diário pode servir para denunciar as maldades do sistema colonial (COUTO, 2006:188). Curiosamente, a perspectiva do padre Antunes - branco, português e jesuíta - não é uma perspectiva do colonizador arrependido da crueldade da colonização. Os seus manuscritos e o livro que planeia escrever serão narrados do ponto de vista de um colonizado, no qual ele simbolicamente se transforma. De facto, Manuel Antunes, na sua opinião, vai mudando de raça e finalmente adopta o nome do escravo morto a bordo do navio, Nimi Nsundi. Essa metamorfose física pode ser um símbolo que representa a passagem da escrita "colonial" sobre a África à reescrita pós-colonial da história africana, contada agora pelos próprios africanos.

Os manuscritos de Manuel Antunes, encontrados entre as posses do padre Silveira, são uma das fontes que servem a Mwadia para construir a sua versão da história colonial. A leitora fictícia, com a ajuda da sua mãe que lê "na areia", torna-se a narradora de um testemunho inventado. A jovem encontra 
nos livros uma ligação entre o passado e o presente. Esta união que anula o tempo cronológico realiza-se, a nível simbólico, através da transformação da leitora em narradora, de um objecto passivo de observação em sujeito activo que narra a história moçambicana.

\section{As regras do jogo: Como construir a narrativa da nação?}

As regras podem ser criadas pelos observadores a partir de uma interpretação subjectiva dos movimentos feitos pelos jogadores (WITTGENSTEIN, 1995:218). No caso dos romances em análise, associaremos as regras do jogo às convenções de géneros literários. As escolhas do autor que segue os esquemas característicos para certo tipo de narrativa ou rompe com eles indica as "regras" que organizam o seu texto. No entanto, é o leitor quem interpreta a aplicação ou transgressão destas "regras do jogo", descobrindo o seu significado. Nesta parte do artigo analisaremos como a utilização de certos géneros literários modaliza o discurso histórico e contribui para a criação da imagem das nações pós-coloniais.

A narração de $A$ gloriosa familia é definida pelo próprio autor como o "romance estórico", 2 em oposição ao romance histórico tradicional, cujos princípios foram baseados no modelo de Walter Scott. De facto, o texto de Pepetela, por mais que descreva os acontecimentos referidos nas crónicas portuguesas ou holandesas (as batalhas, as personagens históricas), não busca representar fielmente a realidade histórica dos tempos dos flamengos. As diferenças e, simultaneamente, as semelhanças entre a narrativa oficial, tal como História geral das guerras angolanas de António de Oliveira Cadornega, e a crónica imaginada pelo escravo, levam à desconstrução pós-moderna da legitimidade do relato histórico. No entanto, é importante destacar que o questionamento da legitimidade da história oficial em A Gloriosa família não é apenas um procedimento formal, artístico. A desconstrução pós-moderna serve aqui como base para a criação de um novo discurso pós-colonial, que procura repensar a narrativa ocidental sobre a África e reformular o seu foco.

2. Esta afirmação aparece na entrevista de Pepetela para o Público ao dia 3 de Janeiro de 1998, citada e referida várias vezes no estudo de Inocência Mata (MATA, 2003:222). 
Este romance "estórico" representa as ideias epistemológicas cruciais para a construção do novo romance histórico, analisado por Seymour Menton (MENTON, 1993). O estudioso da literatura latino-americana destaca como primeira característica a subordinação do princípio da mímese histórica à representação das ideias filosóficas, tais como a ideia de que a verdade histórica é impossível de conhecer (MENTON, 1993:42).

A história de Dom Gonçalo de Silveira incorporada em O outro pé da sereia na forma de manuscritos adopta a convenção de literatura de viagem. Seguindo a estrutura das narrativas típicas da época dos descobrimentos ultramarinos, o relato da viagem de Goa a Moçambique no romance coutiano inclui a descrição detalhada dos preparativos para o embarque e dos objectivos missionários da expedição (COUTO, 2006:61), informação sobre a vida social dos povos nativos (por exemplo, a escravatura entre os africanos; COUTO, 2006:300) ou a representação de cerimónias practicadas pelos escravos, a exemplo do batuque organizado para purificar o navio depois da morte de Nimi Nsundi (COUTO, 2006:239-243). Porém, o narrador extradiagético contrapõe a visão dos colonizadores, como do jesuíta Dom Gonçalo, com as opiniões dos "outros", nomeadamente os escravos (Nimi Nsundi, Xilundo) e os indianos (Dia Kumari, o médico Fernandes), contando a história dos colonizados e não dos colonizadores.

A aplicação dos géneros clássicos da literatura europeia (o romance histórico e a narrativa de viagem) e a transgressão das suas regras, na narrativa dos romances de Pepetela e Mia Couto, permite desconstruir a visão do mundo tradicionalmente representada nestas formas de discurso. Como argumenta Padmini Mongia, a inovação formal é uma das importantes ferramentas da escrita pós-colonial no questionamento do pensamento estabelecido (MONGIA, 2004:156). Assim, os dois textos em análise demonstram não apenas uma mudança formal, mas, sobretudo, uma viragem no pensamento sobre a história colonial e a sua importância para a constituição das nações angolana e moçambicana.

\section{O jogo da reescrita e a imagem da nação pós-colonial}

A relação entre a palavra e o seu referente, o conceito que representa, é uma das questões essenciais no estudo wittgensteiniano do discurso linguís- 
tico. No entanto, a relação cognitiva significante/significado nem sempre é unívoca e absoluta, mas, ao contrário, depende do uso da palavra num contexto determinado. $\mathrm{O}$ acto de reescrita é um jogo que consiste em apresentar o mesmo referente sob palavras distintas.

Como influi o contexto na percepção do objecto descrito? Será que um texto literário pode recriar a imagem de uma nação e ajudar a construir a identidade do seu povo? Como a narrativa pós-colonial introduz novos contextos e novos significados no discurso sobre o colonialismo? Nesta parte do nosso ensaio analisaremos as representações do passado colonial em A gloriosa familia e O outro pé da sereia, e procuraremos ver como estes romances constroem, ou reconstroem, a história africana, forjando, deste modo, as identidades nacionais angolana e moçambicana.

Em A gloriosa família, o narrador cria um documento fictício, no qual a impressão da congruência entre a "realidade" literária e a realidade histórica fica, alternadamente, construída ou desconstruída, principalmente através dos comentários meta-discursivos do narrador. Em seguida, as referências a História geral de guerras angolanas, juntamente com as epígrafes retiradas de várias fontes historiográficas, tais como cartas ou relatórios, são confrontadas com a narração subjectiva e imaginativa do escravo de Baltazar Van Dum. Inocência Mata fortemente destaca a importância da "paródica relação metatextual que se estabelece entre o discurso do autor textual (que manipula as epígrafes) e o do narrador-personagem" (MATA, 2003:214) para a desconstrução da legitimidade da narrativa colonial.

O diálogo intertextual com os textos históricos em A gloriosa família pode ser observado também ao nível da trama. De facto, António de Oliveira Cadornega aparece como uma das personagens do romance e o processo da recolha de informação e da escrita da sua crónica formam parte da acção do romance. As passagens meta-literárias sobre as reflexões éticas que o cronista recriado na realidade pepeteliana podia ter, relativamente ao seu trabalho, reforçam o questionamento da legitimidade das fontes históricas. Os pensamentos de Cadornega (PEPETELA, 2009:260) e do pintor-cronista Barlaeus (PEPETELA, 2009:146), que também pertence ao grupo de figuras históricas no mundo de A gloriosa família, revelam de forma irónica e paródica que toda a representação da realidade é, em certo grau, necessariamente parcial, generalizadora e determinada pela perspectiva que adopta o seu criador. 
Neste contexto, a Luanda de Pepetela é representada a partir da perspectiva do narrador-escravo. Este narrador na posição do estrangeiro deslocado do seu território e da sua cultura (o escravo nasceu na corte de Jinga, uma soberana africana, e foi oferecido a Baltazar Van Dum) apresenta a cidade angolana e os seus habitantes do ponto de vista de um "outro". Um "outro" que consegue aceitar duas explicações, a científica e a mágica, para o mesmo fenómeno (a proibição de beber água no rio como consequência da poluição ou dos maus espíritos, PEPETELA, 2009:31); um "outro" que interroga a nacionalidade dos moradores de Luanda que passa do domínio português ao holandês (PEPETELA, 2009:172); um "outro" que percebe as diferenças culturais entre os europeus e os africanos, que se manifestam, por exemplo, no caso do comércio entre os holandeses e o aristocrata congolense (PEPETELA, 2009:216).

O seu discurso, que engloba diferentes pontos de vista, é contrastado com a descrição paternalista da África pelos europeus, que directamente relaciona a condição colonizador/colonizado, vencedor/vencido com valores éticos e cognitivos. A Luanda de Pepetela e do seu narrador é um microcosmo heterogéneo onde se entrecruzam as tradições locais com as cristãs, os costumes católicos com os protestantes, as políticas dos holandeses, aliados com o reino de Congo e com a rainha Jinga, e dos portugueses, que procuram apoio dos jagas. É o olhar do "outro" que permite captar o carácter transcultural de Luanda, sem sobrevalorizar ou subestimar a influência social e cultural dos vários grupos cuja presença marcou o desenvolvimento da futura capital angolana.

Em O outro pé da sereia a reescrita da colonização de África é realizada em dois níveis narrativos. Por um lado, os manuscritos da viagem de Dom Gonçalo de Silveira, tal como em A gloriosa família, reproduzem os factos históricos e apresentam-nos sob uma nova perspectiva. Por outro lado, Mwadia, como leitora e narradora fictícia, reconta os acontecimentos passados, o que constitui um outro acto de reescrita. A reinterpretação constante das mesmas viagens demonstra a necessidade da reactualização da história, da sua redefinição e incorporação na vida das personagens contemporâneas e da vida da nação. O passado colonial ganha um aspecto mítico; ${ }^{3}$ é preciso recontá-lo para conseguir voltar ao tempo sagrado e definir a sua própria identidade.

3. Um dos aspectos cruciais do mito é, segundo Mircea Eliade, a sua reactualização periódica através de actos rituais (ELIADE, 1963:19-22). 
De facto, a busca da identidade é uma característica predominante de várias personagens do romance. O americano Benjamin Southman é obsessivamente orientado pela sua ascendência africana; o barbeiro Arcanjo Mistura fabrica a história de espionagem e assassinato, voltando aos tempos de luta contra o governo; a mãe de Mwadia regularmente passeia no centro da vila com as fotos dos familiares que morreram; Mwadia encontra nos livros uma âncora de ligação ao passado. Essa presença marcante da história e da tradição na vida de cada pessoa é abertamente reflectida também nos pensamentos de Nimi Nsundi. O escravo explica na carta à sua amada Dia Kamuri como consegue construir a sua identidade híbrida e flutuante: "Uns dizem que nos dividimos entre religiões. Não nos dividimos: repartimo-nos. A alma é um vento. Pode cobrir mar e terra" (COUTO, 2006:131).

A diversidade cultural é a marca da identidade de Moçambique. De facto, tanto na narrativa contemporânea como na narrativa "colonial", entrecruzam-se personagens de origens distintas (europeia, indiana ou africana) que compõem esta imagem heterogénea. Essa variedade reflecte-se também na escolha das epígrafes dos capítulos. Os manuscritos relativos à viagem do missionário jesuíta começam com as citações de várias fontes historiográficas, entre elas as cartas do padre Silveira, padre António Vieira, António Caiado (um aristocrata português delegado à corte do Monomotapa) etc. Porém, o autor introduz também as obras que interpretam estas fontes sob uma perspectiva moderna (reflexões do monge saxão do século XII, citadas por Edward Said; biografia da vida de Dom Gonçalo de Silveira, da autoria de Bertha Leite). Em contraste com estes paratextos baseados nas fontes históricas, as epígrafes relativas aos capítulos "contemporâneos" citam as personagens mais proeminentes da imaginada Vila Longe (o barbeiro Arcanjo Mistura, o adivinho Lázaro Vivo), e ainda canções e provérbios tradicionais (a canção Chikunda, o provérbio nigeriano).

A variedade de fontes demonstra dois aspectos. Por um lado, a fronteira entre o histórico e o literário nunca é fixa. Por outro lado, a justaposição de citações geneologicamente variadas destaca a necessidade de procurar testemunhos distintos para completar uma história. Esta viagem entre as identidades e perspectivas reflecte perfeitamente as ideias de Mia Couto sobre a tarefa do escritor que é "um viajante de identidades, um contrabandista de almas" (COUTO, 2005:59). 


\section{Conclusão}

A gloriosa família e $O$ outro pé da sereia debruçam-se sobre o passado colonial do continente africano, desenvolvendo um jogo histórico. Os romances angolano e moçambicano reescrevem os acontecimentos conhecidos da historiografia europeia, deslocando a perspectiva daquelas narrativas e, consequentemente, construindo novas abordagens sobre a história, a relação colonial e a identidade das suas nações. Nas duas obras é a voz do narrador (ou dos narradores) que convida o leitor a questionar a objectividade dos relatos, sejam eles oficiais, representados em forma de epígrafes que citam as fontes históricas, ou transmitidos pelos próprios protagonistas, que manipulam os factos, imaginando-os, tal como o escravo de Baltazar Van Dum ou Mwadia durante os seus fingidos transes espirituais. Além disso, o processo desconstrutivo é reforçado pelo confronto de uma narração subjectiva, de autoria de um narrador mudo e analfabeto, com as convenções do romance histórico e da crónica, no caso de A gloriosa família, e pelo confronto de uma narração polifónica construída na perspectiva dos grupos marginalizados, com as convenções da literatura de viagem colonial, no caso de $O$ outro pé da sereia. As versões da história colonial de autoria de Pepetela e Mia Couto apresentam Angola e Moçambique, respectivamente, como nações heterogéneas e culturalmente diversas, cujo passado precisa ser repensado e recontado. Suas narrativas, compostas por jogos que despertam a curiosidade e a atenção do leitor, têm um carácter ambíguo, desconstructivo e simultaneamente criativo. A reescrita da história colonial é, neste contexto, uma busca da ideia das nações, cujo surgimento foi determinado pela colonização europeia. De facto, A gloriosa família e $O$ outro pé da sereia procuram responder à questão "Qual é o significado da história?", ou mais especificamente "Qual é o significado da história colonial?”, reformulando a pergunta crucial na obra de Ludwig Wittgenstein "Qual é o significado da palavra?".

\section{Referências Bibliográficas}

BHABHA, Homi. O Local da Cultura. Trad. Myriam Ávila; Rliana Lourenço de Lima Reis; Gláucia Renate Gonçalves. Belo Horizonte: Editora UFMG, 2005. 
COUTO, Mia. O Outro Pé da Sereia. Lisboa: Caminho, 2006.

COUTO, Mia. Pensatempos: Textos de opinião. Lisboa: Caminho, 2005.

ECO, Umberto. Leitura do Texto Literário: Lector in Fabula. Trad. Mário Brito. Lisboa: Presença, 1979.

ELIADE, Mircea. Aspectos do mito. Trad. Manuela Torres. Lisboa: Edições 70, 1963

LEITE, Ana Mafalda. "Janus-narrador em A Gloriosa Família - ou o Poder Profético da Palavra Narrativa”. In CHAVES, Rita, MACEDO, Tânia (org. ). Portanto... Pepetela. Luanda: Edições Chá de Caxinde, 2002:139-150.

MATA, Inocência. Fiç̧ão e História na Obra de Pepetela: Dimensão Extratextual e Eficácia. [Texto policopiado]. Lisboa: [s. n. ], 2003.

MENTON, Seymour. La Nueva Novela Histórica en la América Latina, 1979-1992. Mexico: Fondo Cultura, 1993.

MONGIA, Padmini. "Medieval Travel in Postcolonial Times: Amitav Ghosh's". In an Antique Land. In HOOPER, Glenn, YOUNGS, Tim (org. ). Perspectives on Travel Writing. Aldershot: Ashgate, 2004:153-165.

MOREIRA, Terezinha Taborda. O Vão da Voz: a Metamorfose do Narrador na Ficção Moçambicana. Belo Horizonte: Editora PUC Minas; Belo Horizonte: Edições Horta Grande, 2005.

PEPETELA. A Gloriosa Família. 6a edição. Lisboa: Dom Quixote, 2009.

WITTGENSTEIN, Ludwig. "Investigações Filosóficas". In Tratado lógico-filosófico. Investigações Filosóficas. Trad. M. S. Lourenço. Lisboa: Fundação Calouste Gulbenkian, 1995.

WITTGENSTEIN, Ludwig. O Livro Castanbo. Trad. Jorge Marques. Lisboa: Edições $70,1992$.

Recebido em 10 de Abril e aprovado em 18 de maio de 2010. 